\title{
O departamento de pessoal atuando: na redução ou eliminação de conflitos entre empregado e empregador
}

\author{
The personnel department acting: in the reduction or elimination of conflicts between employee \\ and employer \\ El departamento de personal actúa: en la reducción o eliminación de conflictos entre empleado y \\ empleador
}

Recebido: 31/10/2021 | Revisado: 08/11/2021 | Aceito: 13/01/2022 | Publicado: 15/01/2022

\author{
Flaviane Martins de Araujo \\ ORCID: https://orcid.org/0000-0001-7734-3202 \\ Faveni- Faculdade Memorial dos Imigrantes, Brasil \\ E-mail: flavi_araujo@hotmail.com
}

\begin{abstract}
Resumo
Os trabalhadores oferecem às empresas seus conhecimentos, habilidade e atitudes, ou seja, disponibilizam em troca de recompensas a sua força de trabalho, proporcionando a dinamização e andamento das atividades no meio organizacional. Torna-se crucial o envolvimento e cooperação de todos nos processos, cabe ao setor de departamento de pessoal atuar como elemento integrador na relação empregado versus empregador; conduzir essas relações dentro dos princípios, valores, visão e missão da empresa; atender os requisitos da lei cumprindo a legislação processual trabalhista e as normas do sistema previdenciário. Este presente trabalho objetiva analisar, compreender e demonstrar o setor de departamento de pessoal atuando junto à gestão de pessoas, esclarecer sua importância nos processos decisórios, manutenção e retenção do capital intelectual no meio organizacional.
\end{abstract}

Palavras-chave: Departamento de pessoal; Práticas trabalhistas; Legislação trabalhista; Tomada de decisão.

\begin{abstract}
Workers offer their knowledge, skills and attitudes to companies, that is, they make their workforce available in exchange for rewards, providing the dynamism and progress of activities in the organizational environment. The involvement and cooperation of everyone in the processes is crucial, it is up to the personnel department sector to act as an integrating element in the employee versus employer relationship; conduct these relationships within the company's principles, values, vision and mission; meet the requirements of the law, complying with labor procedural legislation and the rules of the social security system. This present work aims to analyze, understand and demonstrate the personnel department sector working with people management, clarifying its importance in decision-making, maintenance and retention of intellectual capital in the organizational environment.
\end{abstract}

Keywords: Personnel department; Labor practices; Labor legislation; Decision making.

\section{Resumen}

Los trabajadores ofrecen sus conocimientos, habilidades y actitudes a las empresas, es decir, ponen a disposición su mano de obra a cambio de recompensas, aportando el dinamismo y progreso de las actividades en el entorno organizacional. La implicación y cooperación de todos en los procesos es fundamental, corresponde al sector del departamento de personal actuar como elemento integrador en la relación empleado versus empleador; llevar a cabo estas relaciones dentro de los principios, valores, visión y misión de la empresa; Cumplir con los requisitos de la ley, cumpliendo con la legislación procesal laboral y las normas del sistema de seguridad social. El presente trabajo tiene como objetivo analizar, comprender y demostrar el sector del departamento de personal que trabaja con la gestión de personas, aclarando su importancia en la toma de decisiones, mantenimiento y retención del capital intelectual en el entorno organizacional.

Palabras clave: Departamento de personal; Prácticas laborales; Legislación laboral; Toma de decisiones.

\section{Introdução}

O departamento de pessoal é uma área bastante atrativa para os profissionais interessados em atuar nesse segmento, tendo em vista a necessidade de contratação e acompanhamento dos empregados pertencentes ao quadro de uma empresa. Os diversos procedimentos do setor de departamento de pessoal são fundamentados por leis, que denominam os direitos dos 
empregados, surgindo assim à necessidade de profissional capacitado que possa auxiliar os empregadores no cumprimento de suas respectivas obrigações trabalhistas.

Por conta da falta do cumprimento das obrigações trabalhistas por parte de muitos empresários, vai ocorrendo muitos conflitos entre as partes de uma relação de emprego. Algumas empresas ainda possuem a falta de domínio e devido conhecimento das leis e obrigações trabalhistas, sendo penalizadas e consequentemente contribuem na insatisfação dos trabalhadores em continuar exercendo suas atividades junto à empresa. Em alguns casos não realizam o contrato de trabalho formalmente seguindo o que a Lei pede, ocasionando na omissão dos direitos dos trabalhadores e na sonegação de impostos obrigatórios por parte da empresa.

A legislação trabalhista ao longo do tempo foi sendo modificada e tornando-se bem complexa de acompanhar as suas frequentes alterações. Sendo imprescindível ter bons profissionais nas atividades de pessoal, que sejam conhecedores das frequentes mudanças.

O departamento de pessoal cuida da parte trabalhista dos funcionários de uma empresa, sendo atividades que demandam muita atenção, tendo em vista que cuidam do dia a dia do trabalhador; tendo a CLT (consolidação das leis do trabalho), constituição, os sindicatos, convenções trabalhistas, ou seja, têm vários mecanismos legais constando os direitos dos trabalhadores como ferramentas para usar em seu trabalho. Sendo o departamento de pessoal o responsável por fazer os devidos registros trabalhistas dos colaboradores desde a admissão até a fase de desligamento do mesmo.

Os funcionários exercem um importante papel, pois são os fornecedores da força de trabalho, contribuinte com seus conhecimentos e atividades que ajudem ao alcance dos objetivos organizacionais. O departamento de pessoal acaba sendo dependente e influenciado por diferentes aspectos ocorridos, tais como a cultura predominante, a estrutura da organização, o tipo e tamanho do negócio, ou seja, toda a estruturação organizacional e seus processos internos acabam interferindo no andamento do trabalho do setor.

$\mathrm{O}$ atual trabalho apresenta o seguinte problema: como que o setor de departamento de pessoal atua para prevenir os indesejáveis conflitos ocorridos nas obrigações trabalhistas e ajudam no desenvolvimento organizacional das empresas, visando à redução de conflitos judiciais entre empregadores e empregados.

Espera-se que, em nível acadêmico, o presente trabalho forneça informações ou dados aos interessados no aprofundamento de seus conhecimentos teóricos e práticos. Que venha contribuir à sociedade e aos profissionais que desejam conhecer uma das maneiras que possam auxiliar na manutenção da satisfação dos colaboradores, visando obter melhores resultados e gerar competitividade organizacional.

\section{Metodologia}

Considerando o setor de pessoal como um importante agregador ao ambiente de trabalho e também os objetivos propostos neste trabalho, foi realizada a pesquisa de caráter exploratório e bibliográfica, sendo obtido em livros, artigos, periódico, meios eletrônicos contando com materiais disponíveis na internet como os decretos, leis, portarias e assuntos relacionados ao objeto de estudo, visando enriquecer o estudo e contribuir para a conclusão do trabalho. Para o desenvolvimento dos objetivos propostos, embasei numa metodologia de pesquisa do tipo exploratória, que de acordo com o teórico Gil (2002, p.41) caracteriza-se:

[...] Estas pesquisas têm como objetivo proporcionar maior familiaridade com o problema, com vistas a torná-lo mais explícito ou a constituir hipóteses. Pode-se dizer que estas pesquisas têm como objetivo principal o aprimoramento de ideias ou a descoberta de intuições. Seu planejamento é, portanto, bastante flexível, de modo que possibilite a consideração dos mais variados aspectos relativos ao fato estudado. Na maioria dos casos, essas pesquisas envolvem: (a) levantamento bibliográfico; (b) entrevistas com pessoas que tiveram experiências práticas com o problema pesquisado; e (c) análise de exemplos que "estimulem a compreensão." 
Este trabalho caracteriza-se pelo tipo de pesquisa bibliográfica, a qual Lakatos e Marconi (2003, p. 160) definem pesquisa bibliográfica como "um apanhado geral sobre os principais trabalhos já realizados, revestidos de importância, por serem capazes de fornecer dados atuais e relevantes relacionados com o tema".

Diante do exposto, levantou-se o problema da pesquisa: Qual a contribuição do setor de departamento de pessoal na redução e eliminação de conflitos entre empregado e empregador.

O estudo contou com a colaboração de autores que contribuíram positivamente através de suas obras, tornando-se os referencias teóricos do presente trabalho. São eles: Idalberto Chiavenato, Oliveira, Silva, Berg, Aquino, os quais por meio de suas obras e escritas ajudaram no esclarecimento das questões aqui abordadas e formou uma sólida interlocução cientifica acerca dos pontos de convergência.

Os estudos e os levantamentos de informações nessa seção almejam trazer a fundamentação teórica sobre a temática da pesquisa. Serão apresentados e tratados alguns temas relacionados ao objeto de estudo. De modo geral, a pesquisa versará sobre a eficiência do setor de departamento de pessoal no processo de redução ou eliminação de conflitos entre empregado e empregador.

\subsection{O Departamento de pessoal}

Com o intuito de proteger a classe trabalhadora, foi criada uma legislação específica, a qual o empregador deverá seguir. Segundo Carvalho (2000, p. 85): "Departamento De Pessoal é o setor que executa as tarefas prescritas pelas leis, regulamentos e normas brasileiras e previdenciárias, notadamente o registro, anotação e contabilidade dos principais fatos da vida do empregado na empresa, desde a sua admissão até o seu desligamento".

O departamento de pessoal vai atuar nas orientações as empresas e aos demais interessados, buscando prevenir reclamações trabalhistas, tendo como sua missão principal o trato dos assuntos pertinentes aos empregados. Segundo Oliveira (2010), "o departamento de pessoal é uma sessão que cuida das relações dos empregados com a empresa, tanto no campo social, como no que diz respeito aos direitos e deveres dos empregados".

Realizam inúmeras práticas, todas estão relacionadas com a legislação, e devem seguir uma burocracia de maneira que seja a mais correta possível, pois é sabido que o setor também enfrenta certas dificuldades em cumprir todas as exigências trabalhistas, sendo necessário que os profissionais atuando junto ao setor de pessoal estejam atualizados com a legislação, pois ela está sujeita a constantes mudanças.

O departamento de pessoal funciona como uma espécie de elo que liga uma empresa aos seus funcionários, exercendo papel significativo para a organização. É um setor dentro de uma organização que fica responsável pela organização, administração, e cuidar de toda a rotina de uma relação de emprego, sendo o subsistema da administração de recursos humanos e responsável pelo cumprimento de toda a legislação previdenciária e trabalhista de uma empresa.

Responsável por cuidar: da parte burocrática (relativo à legislação Trabalhista e Previdenciária). É o setor que elabora a folha de pagamento, faz registro das carteiras dos funcionários, calcula as guias do INSS e FGTS para pagamento, cuida da parte demissional, entre outras. Silva $(2009$, p.1)

As rotinas envolvem diversas atividades, tais como: o processo admissional, benefícios, relação sindical, folha de pagamento, transporte, organização de horários, controle de pontos, benefícios, atestados, férias, licença médica, $13^{\circ}$ salário, declaração trabalhistas mensais e anuais, cumprir normas de segurança e higiene do trabalho, encargos sociais, demissão, organização de arquivos contendo documentos relacionados às rotinas de trabalho exigidas em lei,entre outras.

De acordo com Franco (1996, p. 45), "é no setor de Departamento De Pessoal que se encontram todas as informações e registros referentes a cada funcionário da empresa, desde a sua admissão até a sua demissão". 
A função de departamento de pessoal vai exigir planejamento, organização e administração por parte da empresa, e assim poder contribuir para seus fins econômicos como recurso tático para implantar o processo estratégico. (Aquino, 1992).

A Figura 1 representa algumas das atribuições desenvolvidas pelo setor:

Figura 1. Algumas das atribuições desenvolvidas pelo setor.

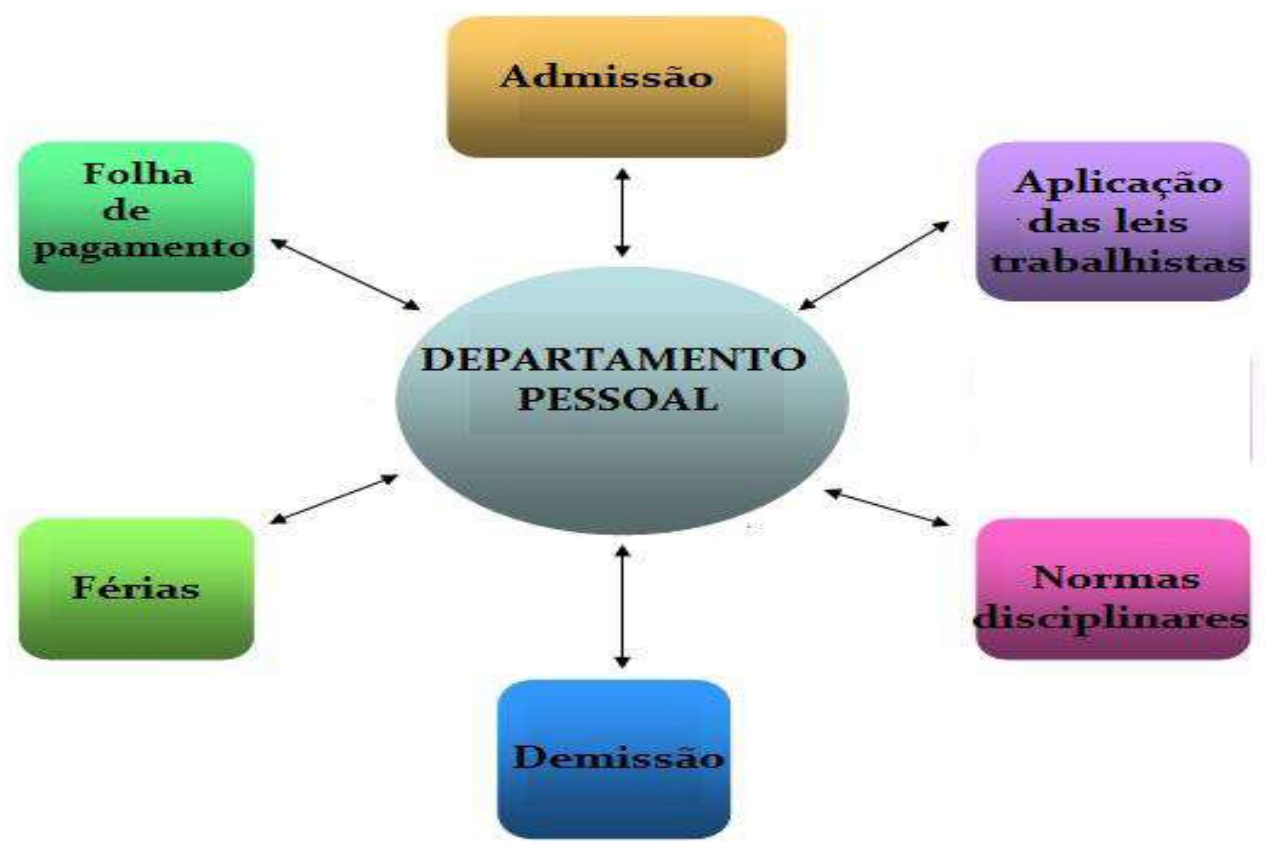

Fonte: Tiossi, M. J. F. \& Ferracini; D. A. R.

As organizações vêm lutando pela sobrevivência e crescimento no mercado, e diante deste fator precisam compreender a importância da boa gestão de seu capital humano, tendo em vista que ocorre frequentemente uma grande infidelidade e rotatividade por parte dos empregados, por vezes decorrendo de fatores de desmotivação com seu local de trabalho, insatisfação com o não cumprimento dos direitos por parte dos empregadores, falta de reconhecimento, atrasos no pagamento de salários, descontos indevidos e benefícios não concedidos, o que acarreta em aumento de custos para empresa com os processos de demissão e novas contratações, queda na produção, redução de espaço no mercado e afeta na insatisfação do cliente.

Diante disso, o Departamento de pessoal deve auxiliar nas tomadas de decisões organizacionais no que tange a melhoria da relação entre empregado e empregador, em conformidade com o cumprimento das leis Trabalhistas. É importante que o setor de departamento de pessoal esteja alinhado e integrado com os demais setores estratégicos organizacionais, trabalhando até mesmo em conjunto com o setor de recursos humanos, pois uma empresa visa alcançar suas metas e objetivos, sendo desta forma, necessário que todos estejam em perfeita sintonia e sejam conhecedores dos fatos e acontecimentos em uma empresa. A melhoria da tecnologia agregou muito no desenvolvimento das tarefas do setor de pessoal e contribuiu na aproximação dos colaboradores e empresa através do uso de ferramentas digitais, atualmente já é possível em muitas organizações ter canais de comunicação por meio digitais, favorecendo a comunicação mais rápida entre as pessoas.

A folha de pagamento consiste em um documento elaborado pelo Departamento De Pessoal que contabiliza todos os lançamentos realizados aos pagamentos e descontos na remuneração do empregado (Oliveira, 2002). Tendo a empresa de obrigatoriedade de confeccionar a folha de pagamento de todo o seu pessoal, conforme afirma Oliveira (2002, p. 17):

O uso da folha de pagamento é obrigatório para o empregador, conforme a lei $\mathrm{n}^{\circ} 8.212 / 91$ art. 32, inciso I, da Consolidação da Legislação Previdenciária - CLP. Ela pode ser feita à mão (manuscrita) ou por meio de processo 
mecânico ou eletrônico. Nela são registrados mensalmente todos os proventos e descontos dos empregados. Deve ficar a disposição da fiscalização, da auditoria interna e externa, estar sempre pronta para oferecer informações necessárias à continuidade da empresa.

O acompanhamento da frequência é uma atividade também muito importante e que irá influenciar na remuneração dos colaboradores, sendo atribuições do departamento de pessoal todo o gerenciamento da folha de pagamento, Representação junto a órgãos oficiais e fiscais, cuidar das admissões e demissões, eSocial, benefícios, férias, controle de ponto e demais rotinas burocráticas e trabalhistas relacionadas aos colaboradores, devendo assim ter um bom gerenciamento.

O funcionário do departamento de pessoal deve manter-se atento às novidades disponibilizadas no mercado, no que tange ao uso de tecnologias como forma de melhorar suas atividades e acompanhar rapidamente todas as mudanças na legislação. È um setor que precisar estar disponível para atender o seu pessoal, ouvi-los, sanar suas dúvidas e orientá-los nas questões burocráticas da relação trabalhista. Possui a responsabilidade de manter toda a parte documental organizada e devidamente registrada, com fácil acesso e garantindo que as leis sejam cumpridas.

\subsection{História e evolução}

$\mathrm{Na}$ época da escravidão os senhores davam poder as pessoas conhecidas como capitão para se responsabilizarem e cuidarem dos escravos, os quais eram fornecedores de trabalho e vistos como máquinas, sem direito a nada. Esses capitães seriam hoje os profissionais da área de departamento de pessoal, que auxiliam na relação das partes do trabalho.

A partir de 1888 com o fim da escravidão no Brasil, começou-se a ter discussões a respeito de direitos e modos de solucionar os conflitos existentes entre os empregados e seus patrões. De acordo com os estudos da administração, o capital humano não era valorizado antigamente, sendo os trabalhadores utilizados apenas para serem cumpridores de suas funções em troca de recebimento de uma quantia financeira. Era empregada uma forte supervisão com decisões centralizadas, seguia a ideia do "homo economicus" da teoria Clássica.

A revolução industrial (Século XIX e XX) foi um período de grande desenvolvimento industrial e tecnológico iniciado na Inglaterra, que se espalhou pelo mundo, causando muitas transformações para o cenário econômico e social do mundo. Os homens foram sendo substituídos por máquinas e ferramentas, viviam em condições precárias e por vezes desumanas de trabalho, com salários baixos, submetidos a jornadas de trabalho elevadas, sendo formado um número crescente e enorme de pessoas insatisfeitas e desempregadas. Predominava a aplicação de punições severas, contribuindo a um clima de desconforto e medo entre trabalhadores, que se tornavam manipulados e vistos como fornecedor de trabalho, ou seja, eram vistos como uma peça de máquina, tratados como objetos que eram orientados ao modo de executar suas tarefas sem poderem dar qualquer tipo de sugestão, devendo obedecer a certos ritmos da produção maquinal imposto pelos superiores.

Por conta dos efeitos desta mecanização da produção foi ocorrendo greves e revoltas sociais, servindo como inspiração para criação de movimentos organizados por trabalhadores de diversos locais do mundo, voltados para defender os seus direitos de trabalho.

A Revolução Industrial trouxe pontos negativos, mas também contribuiu de forma positiva ao desenvolvimento do Brasil, tendo como umas de suas benfeitorias, a possibilidade de redução de custos e aumento da produção, consequentemente tornando os produtos mais baratos, gerou mais empregos, diminuindo a dependência brasileira de produtos importados, teve progresso nos meios de transportes, teve a criação de sindicatos que lutavam por melhores salários e condições de trabalho.

O "homos economicus" foi sendo substituído pelo novo conceito de " o "homem social", dando maior ênfase nas pessoas em si, e posteriormente surgiu a "teoria das relações humanas", baseada na maneira que a pessoa se comporta, dando atenção a sua motivação no trabalho e possibilitando maior flexibilidade para as empresas. A classe trabalhadora passou a exigir e lutar por participação nas decisões organizacionais e não mais eram vistas como uma mera peça de máquina. 
Com o crescente surgimento de empresas, ainda não existia legislação que formalizasse a relação de emprego, os patrões apenas forneciam o sustento aos trabalhadores. Durante o governo de Getúlio Vargas em 1930, foi criado o Ministério do Trabalho, que estabeleceu alguns direitos e mudanças na relação de trabalho, instituiu a criação da carteira de trabalho, cuidou do horário de trabalho. Em 1934 a primeira Constituição a tratar de Direito do Trabalho, garantia a liberdade sindical, isonomia salarial, jornada de oito horas de trabalho, salário mínimo, proteção do trabalho da mulher, férias remuneradas, repouso semanal e exploração de mão de obra infantil.

O aparecimento do Departamento de Pessoal ocorreu quando os empregados se tornaram fator de produção cujos custos deviam ser administrados tão racionalmente quantos os custos dos outros fatores de produção. A raiz do que viria a ser chamado posteriormente de administração de recursos humanos estaria na necessidade da grande corporação de gerenciar os funcionários como custos, o elemento diferenciador de competitividade na época. (Fischer, 2002, p. 20).

A CLT (Consolidação das Leis do Trabalho) surgiu como uma necessidade constitucional e foi criada por meio do Decreto-lei n$^{\circ} 5.452$, de $1^{\circ}$ de maio de 1943 e sancionada pelo presidente daquela época Getúlio Vargas, durante o período conhecido como Estado Novo.Foi criada também no mesmo local e dia do ano a Justiça do Trabalho. A Consolidação juntamente com a Justiça do Trabalho regula as relações coletivas e individuais do trabalho, estabelecendo e garantindo os direitos e obrigações que deverão existir na relação entre empregadores e empregados.

Todo o Homem que trabalha tem direito a uma remuneração justa e satisfatória, que lhe assegure, assim como à sua família, uma existência compatível com a dignidade humana, e a que se acrescentarão, se necessário, outros meios de proteção social. (Declaração Universal dos Direitos do Homem).

Entre os direitos reservados aos empregados estão os de receber: Salário, vale transporte, $13^{\circ}$ salário, hora extra, hora noturna, verbas rescisórias, adicionais de insalubridade e periculosidade, depósito de FGTS e férias remuneradas. Para Gonçalves (2005, p. 69): "Empregado é toda pessoa física que presta serviços habitualmente ao empregador, sob dependência deste e mediante salário".

De acordo com o art. $3^{\circ}$ da CLT (Brasil, 1943):

a) o empregado é sempre pessoa física;

b) há habitualidade na prestação de serviço;

c) existe subordinação (cumprimento de ordens);

d) há obrigatoriedade de pagamento de salários.

De acordo com art. $2^{\circ}$ da CLT, empregador é "a empresa, individual ou coletiva, que, assumindo os riscos da atividade econômica, admite, assalaria e dirige a prestação pessoal de serviço" (Brasil, 1943, não paginado).

A partir do momento que foi instituído os direitos e obrigações trabalhistas o departamento de pessoal trabalharia seguindo a justiça do trabalho e a consequente proteção dos direitos da classe trabalhadora.

\subsection{Conflitos Organizacionais}

Na opinião de Chiavenato (2004), "O conflito é muito mais do que um simples acordo ou divergência: constitui uma interferência ativa ou passiva, mas deliberada, para impor um bloqueio sobre a tentativa de outra parte de alcançar os seus objetivos". O ser humano possui opiniões, atitudes, personalidades e fatores motivacionais bem distintos, podendo ocorrer momentos de divergências e choques de ideias entre as relações interpessoais no ambiente empresarial, sendo importante a boa gestão por parte da empresa na sua solução.

Berg (2012), afirma que: "O conflito nos tempos atuais é inevitável e sempre evidente. Entretanto, compreendê-lo, e saber lidar com ele, é fundamental para o seu sucesso pessoal e profissional”. Tendo em vista que o ambiente organizacional é 
composto por pessoas que são dotadas de perspectivas e gostos diferentes entre si, logo, é possível ocorrer situações conflituosas, em dado momentos.

Segundo Chiavenato (2004), "O conflito ocorre pela diferença de objetivos e interesses pessoais, e é parte inevitável da natureza humana; constitui o lado oposto da cooperação e da colaboração, a palavra conflito está ligada à desacordo, discórdia". A empresa deve se antecipar a possíveis situações que poderá gerar uma insatisfação ou caracterizar uma conduta empresarial que gere uma situação negativa por parte do empregado.

Vale acrescentar, que os conflitos existentes na relação entre empregado versus empregador podem interferir positivamente impulsionando mudanças significativas e necessárias, mas também podem ser conflitos negativos, os quais acarretarão problemas desnecessários, desconstruir valores, acarretando em prejuízos para os empregados e empresa.

\subsection{A Gestão organizacional}

As organizações existem para servirem as pessoas estão se expandindo, sendo impulsionadas pela grande competitividade e exigência por parte da sociedade. Vale lembrar que são entidades com planejamento, organizadas, dirigidas e com forte controle por parte da alta administração. Segundo Cury (2000, p. 116): “...a organização é um sistema planejado de esforço cooperativo no qual cada participante tem um papel definido a desempenhar e deveres e tarefas a executar".

Os autores Herbert Simon, Meireles e Paixão chegaram ao seguinte conceito: “a organização é um artefato que pode ser abordado como um conjunto articulado de pessoas, métodos e recursos materiais, projetado para um dado fim e balizado por um conjunto de imperativos determinantes (crenças, valores, culturas etc.). (Meireles, 2003, p. 46)”.

A respeito da origem organizacional Coelho entende que:

[...] Na Antiguidade, roupas e víveres eram produzidos na própria casa, para os seus moradores; apenas os excedentes eventuais eram trocados entre vizinhos ou na praça. [...] Alguns povos da Antiguidade, como os fenícios, destacaramse intensificando as trocas e, com isto, estimularam a produção de bens destinados especificamente à venda. Esta atividade de fins econômicos, o comércio, expandiu-se com extraordinário vigor. (Coelho, 2004, p. 5).

Atualmente o mundo requer organizações mais dinâmicas e que saibam acompanhar a alta complexidade e volatilidade dos negócios empresariais, cabendo às empresas buscarem maneiras de se prepararem para alcançarem os melhores resultados. É importante aprender com as falhas históricas vividas, mas focar em buscar os ajustes para sempre acertar na gerencia de seus processos organizacionais.

Por conta das frequentes mudanças e avanços ocorridos nas últimas décadas, as empresas estão buscando aprimorar a sua gestão, com o intuito de melhorar seus resultados e cumprir com sua missão institucional. As empresas passaram a valorizar o capital humano, identificando que são elas que contribuem para o alcance do sucesso ou insucesso.

Segundo Fischer (2002), “o mundo está em processo de globalização, isto é fato, principalmente nos planos econômico, tecnológico e das comunicações, o que tem ocasionado diversas mudanças na gestão administrativa das empresas". De acordo com este presente cenário de mudanças, cabe à organização estar afinada com suas estratégias e atividades desenvolvidas, sendo fortalecida por uma gestão integrada e participativa.

Chiavenato (1999) considera que a Gestão de pessoas "é o conjunto de políticas e práticas necessárias para conduzir os aspectos da posição gerencial relacionados com as pessoas ou recursos humanos". No tocante a essas práticas e políticas, o setor de departamento de pessoal atua na administração da força de trabalho de uma empresa, tendo em vista que as pessoas são consideradas um dos principais ativos.

Chiavenato (2001) informa que: 
As pessoas constituem o principal ativo da organização. Daí a necessidade de tornar as organizações mais conscientes e atentas para os seus funcionários. As organizações bem-sucedidas estão percebendo que somente podem crescer prosperar e manter sua continuidade se forem capazes de aperfeiçoar o retorno sobre os investimentos de todos os parceiros, principalmente o dos empregados. Quando uma organização está realmente voltada para as pessoas, a sua filosofia global e sua cultura organizacional passam a refletir essa crença. A Gestão de pessoas nas organizações é a função que permite a colaboração eficaz das pessoas - empregado, funcionários, recursos humanos ou qualquer denominação usada - para alcançar os objetivos organizacionais e os individuais (...) As pessoas podem limitar ou ampliar as fraquezas ou forças organizacionais, dependendo do modo como são tratadas. Para que os objetivos da Gestão de Pessoas sejam alcançados, é preciso que os gestores tratem as pessoas como elementos básicos para o alcance da eficácia da organização.

\section{Conclusão}

O presente trabalho teve o objetivo de expor a importância das atividades do setor de departamento de pessoal, no sentido de proporcionar uma melhoria no formal relacionamento entre empregador e empregado, visando evitar futuras reclamações trabalhistas decorrentes de procedimentos ilegais.

A pesquisa demonstra que a área de departamento de pessoal funciona como elemento essencial para uma boa administração de empresa, devido à necessidade de contratação de indivíduos para execução de suas atividades organizacionais. O profissional atuante nessa área é responsável por cuidar de toda a parte burocrática no que tange aos documentos e procedimentos primordiais que trata a Consolidação das Leis Trabalhistas, previdenciárias e regulamento internos das empresas, mantendo uma excelente relação entre as partes.

O departamento de pessoal é composto basicamente por três diferentes rotinas, sendo elas: A admissão de pessoal, a manutenção, e o desligamento do colaborador, onde são desenvolvidas atividades nos processos de direcionamento, organização de documentos e administração pessoal, lidando com os colaboradores e suas perspectivas carreiras.

Na fase de admissão de pessoal são realizados todos os procedimentos necessários para a construção e formalização de um contrato de trabalho do empregado dentro das normas jurídicas exigentes, formalizando a sua relação e vínculo junto à empresa.

A manutenção da relação consiste em atividades para ter o controle de frequência dos empregados, elaborar a folha de pagamento com os seus registros, descontos, proventos, pagamentos das exigências, impostos e obrigações tributárias.

O desligamento de pessoal é a última etapa da relação empregatícia, tendo como atividades: cuidar de todos os procedimentos para o formal desligamento e da quitação das verbas rescisórias. Sendo importante realizar um bom término de relação de trabalho, a empresa cumprindo e honrando seus deveres e o empregado da mesma maneira, podendo fazer uso de entrevista de desligamento para obter um feedback acerca da empresa na visão do trabalhador que está sendo desligado, buscando fazer os registros dos pontos negativos e positivos relatados.

A pesquisa proporcionou bons resultados no que tange aos objetivos traçados, agregando excelentes conhecimentos sobre o assunto. Para que se tenha uma boa relação empregatícia é necessário contar com bons profissionais de departamento de pessoal trabalhando aliados a uma boa gestão organizacional, de modo que busquem atuar nas tomadas de decisões e momentos necessários, visando contribuir positivamente na imagem da empresa e ter trabalhadores satisfeitos.

O empregado ao longo do tempo foi sendo protegido por leis e atividades que formalizam legalmente a sua relação de emprego junto a uma organização. Com tantas evoluções no campo do direito do trabalho, é de extrema importância a presença de profissionais zelosos, prudentes e íntegros em suas ações. A legislação nessa área é bem farta e constantemente sofre alterações, o que torna essencial o uso frequente de pesquisas e atualização por parte dos profissionais atuante no departamento de pessoal de uma empresa privada ou pública.

O departamento de pessoal contribuirá positivamente na redução de possíveis e eventuais conflitos que possam ocorrer na relação entre patrão e empregado quando executam as atribuições dentro da lei. Sendo assim, pode-se concluir que o 
melhor caminho para evitar o insucesso e problemas com ações, que podem gerar prejuízos, é buscar seguir corretamente o que é expresso pela legislação trabalhista e normas Previdenciárias, ter a perfeita compreensão das leis para atender os requisitos legais. Este setor direcionará, de modo estratégico, o processo de gestão de pessoas na perspectiva de obter melhoria de resultados da organização.

Os resultados da pesquisa demonstram que para que uma organização possa alcançar a sua boa produtividade é necessário contar com departamentos que são indispensáveis a sua rotina, sendo o departamento de pessoal o responsável pela entrega de todas as obrigações acessórias de uma empresa, cuidando da parte burocrática e da relação financeira existente entre o empregador e seus funcionários, atividade que se inicia com o registro dos colaboradores selecionados por parte do setor de recrutamento e seleção, fazendo com que todos os direitos sejam cumpridos e respeitados de acordo com as legislações trabalhistas e previdenciárias vigentes e a empresa esteja dentro de legislações específicas.

Por fim, espera-se que essa pesquisa venha contribuir para a área de gestão de pessoas e fornecer embasamento no que tange ao tema proposto, visando dotar de eficiência o processo de departamento de pessoal, promover melhorias nas discussões e debates acerca do assunto, e que essa temática abordada esteja mais presente nas rotinas empresariais e em temas de estudo.

\section{Referências}

Aquino, C. P. de. (1992). Administração de recursos humanos: uma introdução. Atlas 270 p.

Brasil. Lei no 13.467/2017, de 13 de julho de 2017. http://www.planalto.gov.br/ccivil_03/_ato2015-2018/2017/lei/113467.htm.

Brondi, B., Bermúdez, R., \& Raúl, Z. (2007). Departamento de Pessoal Modelo. (4a ed.), IOB.

Carvalho, P. C. de. (2000) Recursos Humanos. Alínea, 222p.

Chiavenato, I. (1999). Gestão de pessoas: o novo papel dos recursos humanos nas organizações. Rio de Janeiro: Editora Campus.

Chiavenato, I. (2001). Gestão de Pessoas. (3a ed.), Campus.

Chiavenato, I. Gestão de Pessoas. https://gennegociosegestao.com.br/objetivos-gestao-do-talento-humano.

Chiavenato, I. (2002). Recursos Humanos. Atlas 631 p.

CLT - Consolidação das Leis do Trabalho. 1943

Coelho, F. U. (2004) Manual de direito comercial. Saraiva,

Cury, A. (2000). Organização e métodos: uma visão holística. (7a ed.), Atlas

Evolução Histórica do Direito do Trabalho no Brasil. http://www.jurisway.org.br/v2/dhall.asp?id_dh=4553.

Fabiano. Sistema Trabalhista.https://www.realguide.com.br/o-direito-sistemico-e-a-resolucao-de-conflitos-trabalhistas/ .

Fernandes, A. Departamento De Pessoal: Sua Importância, Funções, Rotinas. https://www.pontotel.com.br/departamentopessoal/

Fischer, A. L. (2002). Um resgate conceitual e histórico dos modelos de gestão de pessoas. In: FLEURY, Maria Teresa Leme (Org.). As pessoas na organização. Gente, 11-34.

Fleury, M., (2002). As pessoas na organização. Editora Gente.

Fleury, M. T. L., \& Fischer, R. M. (1998). Processo e relações do trabalho no Brasil. Atlas

Fragoso, C. As diferenças entre Departamento de Recursos Humanos e Departamento Pessoal. 2015. http://www.rhportal.com.br/artigos-rh/as-diferenas-entredepartamento-de-recursos-humanos-e-departamento-pessoal/.

Franco, H. (1996). Contabilidade Industrial. (9a ed.), Atlas.

Fundação IDEPAC para Desenvolvimento Profissional, Departamento De Pessoal. 2009. http://www.idepac.org.br/apostilas/dept opessoalavulso.pdf.

Gil, A. C. (2002). Como elabora projetos de pesquisa. (4aed.). Atlas.

Gonçalves, G. (2005). Rotinas trabalhistas de A a Z. Juruá

IBC, Equipe. Tipos de Conflitos nas Organizações.https://www.ibccoaching.com.br/portal/conheca-os-tipos-de-conflitos-nasorganizacoes.

Mannric. (2006). “CLT - Legislação Trabalhista e Previdenciária”. Constituição Federal. (7a ed.), Revista dos Tribunais. 
Research, Society and Development, v. 11, n. 1, e55311122590, 2022

(CC BY 4.0) | ISSN 2525-3409 | DOI: http://dx.doi.org/10.33448/rsd-v11i1.22590

Meireles, M. (2003). Teorias da administração: clássicas e modernas. Futura

Mouret, S. Rehvolução Industrial no Brasil. http://www.estudopratico.com.br/revolucao-industrial-no-brasil/>08 de julho de 2014.

Neto, J. Reforma ou deforma administrativa. HTTPS://JUS.COM. BR/ARTIGOS/86047/REFORMA-OU-DEFORMA-ADMINISTRATIVA/2.

Oliveira, A. G. de. (2010). Departamento de Pessoal: um estudo de caso sobre os procedimentos e informações contábeis geradas. www.eduvalesl.edu.br/site/edicao/edicao-18.pdf.

Oliveira, A. G. de. Departamento Pessoal: um estudo de caso sobre os procedimentos e informações contábeis geradas, em uma empresa industrial de plásticos no município de Rondonópolis - MT. 2010. 14 f. Trabalho de Conclusão de Curso (Graduação em Ciências Contábeis) - Faculdade de Ciências Sociais Aplicadas do Vale de São Lourenço, Jaciara/MT. http://eduvalesl.revista.inf.br/imagens_arquivos/arquivos_destaque/h2V7spY1M4t1boW_2015-12-18-22-35.pdf.

Rev. Eletrônica Organ. Soc., Iturama (MG), 7(7), 44-662018 10.29031/ros.v7i7.334.

Silva, W. R. da., \& Rodrigues, C. M. C. (2007). Motivação nas Organizações. Atlas.

Toledo, A., Vaz, M., \& Céspedes, L. (2006) Constituição Federal, CLT, Legislação Previdência. Saraiva 